\title{
Performance analysis of grid-integrated brushless doubly fed reluctance generator-based wind turbine: modelling, control and simulation
}

\author{
Mahmoud Rihan $^{1} \cdot$ M. Nasrallah ${ }^{1} \cdot$ Barkat Hasanin $^{2}$
}

Received: 24 September 2019 / Accepted: 12 December 2019 / Published online: 19 December 2019

(c) Springer Nature Switzerland AG 2019

\begin{abstract}
Due to the absence of the rotor windings, the brushless doubly fed reluctance generator (BDFRG) presented a much better efficiency with less complicated control and modelling than that introduced by the brushless doubly fed induction generator. As a result, the BDFRG gained more preference than that of the doubly fed induction generator. Moreover, this result led to the emerging of the (BDFRG) as one of the most promising generators in the new modern wind turbines. This paper introduces modelling as well as control strategy for the grid-connected BDFRG-based wind turbine systems. This study was carried out using MATLAB/Simulink environment.
\end{abstract}

Keywords Modelling $\cdot$ Simulation $\cdot$ BDFRG $\cdot$ Wind turbine $\cdot$ Control

\begin{tabular}{|c|c|c|c|}
\hline \multicolumn{2}{|c|}{ Abbreviations } & $r_{\mathrm{p}}$ & Resistance of power winding \\
\hline \multicolumn{2}{|r|}{ Wind energy conversion system } & $r_{\mathrm{c}}$ & Resistance of control winding \\
\hline BDFRG & Brushless doubly fed reluctance generator & $\lambda_{\mathrm{dp}}$ & Direct flux component for power winding \\
\hline BDFIG & Brushless doubly fed induction generator & $\lambda_{\mathrm{qp}}$ & Quadrature flux component for power winding \\
\hline IFOC & Indirect field-oriented control & $\lambda_{\mathrm{dc}}$ & Direct flux component for control winding \\
\hline MPPT & Maximum power point tracking & $\lambda_{\mathrm{qc}}$ & Quadrature flux component for control \\
\hline MSC & Machine-side converter & & winding \\
\hline GSC & Grid-side converter & $i_{\mathrm{dp}}$ & Direct current component for power winding \\
\hline SPWM & Sinusoidal pulse-width modulation & $i_{\mathrm{qp}}$ & Quadrature current component for power \\
\hline $\begin{array}{l}\text { IFOC } \\
\text { PLL }\end{array}$ & $\begin{array}{l}\text { Indirect field-orient } \\
\text { Phase-locked loop }\end{array}$ & $i_{\mathrm{d}}$ & $\begin{array}{l}\text { winding } \\
\text { Direct current component for control winding }\end{array}$ \\
\hline \multicolumn{2}{|c|}{ List of symbols } & $i_{\mathrm{qc}}$ & Quadrature current component for control \\
\hline$\omega$ & Speed of reference frame of power winding & & $\ln$ \\
\hline$\omega_{\mathrm{r}}$ & Electrical speed of rotor & $L_{p}$ & $\begin{array}{l}\text { Inductance of power windıng } \\
\text { Inductance of control winding }\end{array}$ \\
\hline$v_{\mathrm{dp}}$ & Direct voltage component for power winding & $\begin{array}{l}L_{c} \\
L_{n c}\end{array}$ & Mutual inductance between power and control \\
\hline$v_{\mathrm{qp}}$ & $\begin{array}{l}\text { Quadrature voltage component for power } \\
\text { winding }\end{array}$ & & winding \\
\hline$v_{\mathrm{dc}}$ & Direct voltage component for control winding & $T_{\mathrm{e}}$ & Electrical torque produced from the generator \\
\hline$v_{\mathrm{qc}}$ & $\begin{array}{l}\text { Quadrature voltage component for control } \\
\text { winding }\end{array}$ & $\begin{array}{l}p_{\mathrm{r}} \\
T_{\mathrm{m}}\end{array}$ & $\begin{array}{l}\text { Number of poles for rotor } \\
\text { Mechanical torque from turbine }\end{array}$ \\
\hline
\end{tabular}

\footnotetext{
$\triangle$ M. Nasrallah, nasrallah_1@yahoo.com; Mahmoud Rihan, mahmoudrihan@eng.svu.edu.eg; Barkat Hasanin, bmhsaneen@yahoo.com | 'Department of Electrical Engineering, University of South Valley, Qena, Egypt. ${ }^{2}$ Department of Electrical Engineering, University of Al-Azhar, Qena, Egypt.
} 


$\begin{array}{ll}n_{\mathrm{g}} & \text { Turns ratio for gear box } \\ \omega_{\mathrm{rm}} & \text { Mechanical speed of rotor } \\ J_{\mathrm{r}} & \text { Moment of inertia for wind turbine } \\ J_{\mathrm{g}} & \text { Moment of inertia for generator } \\ D_{1} & \text { Constant } \\ \omega_{\mathrm{p}} & \text { Angular speed for power winding } \\ \omega_{\mathrm{s}} & \text { Angular speed for control winding } \\ P_{\mathrm{t}} & \text { Mechanical power from wind turbine } \\ \rho & \text { Air density } \\ C_{\mathrm{p}} & \text { Power coefficient } \\ R & \text { Wind turbine blade radius } \\ \beta & \text { Pitch angle of blade } \\ V_{\mathrm{w}} & \text { Wind speed } \\ \lambda & \text { Tip-speed ratio } \\ \theta_{\mathrm{p}} & \text { Primary flux angle } \\ \theta_{\mathrm{g}} & \text { Grid current angle }\end{array}$

\section{Introduction}

Doubly fed variable-speed WECS has a series of advantages over both fixed-speed WECS and variable-resistance configuration (a type of variable-speed WECS), such as

(1) Doubly fed variable-speed WECS improves the efficiency of energy conversion, because the doubly fed variable-speed WECS has the ability to extend generator speed range $( \pm 30 \%)$. Moreover, the doubly fed variable-speed WECS improves dynamic performance.

(2) Doubly fed variable-speed WECS has the ability to decrease the mechanical stress mainly caused by wind fluctuations. This result has a positive impact on the design of the structure and mechanical parts of the turbine. Moreover, this result led to the creation of a large wind turbines.

Doubly fed machines became much popular. Moreover, they became a research field for a lot of researchers. This is due to their capability to be used as a partially rated converter. In particular, the BDFIG is preferred than the conventional doubly fed induction machine; this preference is based on the ability to eliminate the slip rings. However, the BDFIG with time loss popularity mainly due to the rotor losses and the rotor construction is complicated [1]. Sometimes, the BDFRG is considered as an anther solution to the problems of BDFIG and DFIG [2]. After the improvement of the reluctance rotor, the BDFRG has a simpler control and a higher efficiency than those obtained by the BDFIG. These reasons increased the popularity of the BDFRG in comparison with other types of doubly fed machines. Due to the information mentioned above, the BDFRG is considered a preferable choice for using doubly fed machines with wind turbines.

\section{Brushless doubly fed reluctance generator}

The BDFRG mainly consists of two groups of three-phase distributed windings on its stator. The two groups of the three-phase distributed windings on the stator have different pole numbers and different applied frequencies, as illustrated in Fig. 1. The important condition for producing torque in this machine is its rotor must contain pole number equal to half the sum of pole numbers of the two stator windings. The shaft torque depends on the magnetic coupling between these two windings $[3,4]$. The power winding (or primary winding) has a direct connection with the network (or grid), while the control winding (or secondary winding) is connected to the network via two partially rated converters. These converters are called machine-side converter and grid-side converter; a capacitance is found between them. This capacitance controlled in the power flow in the two directions. The BDFRG has a greater efficiency, because the rotor windings are absent. This result led to the BDFRG to have a modelling and control much simpler than a modelling and control for the BDFIG [5]. The control of the generator aimed to extract
Fig. 1 Conceptual diagram of BDFRG

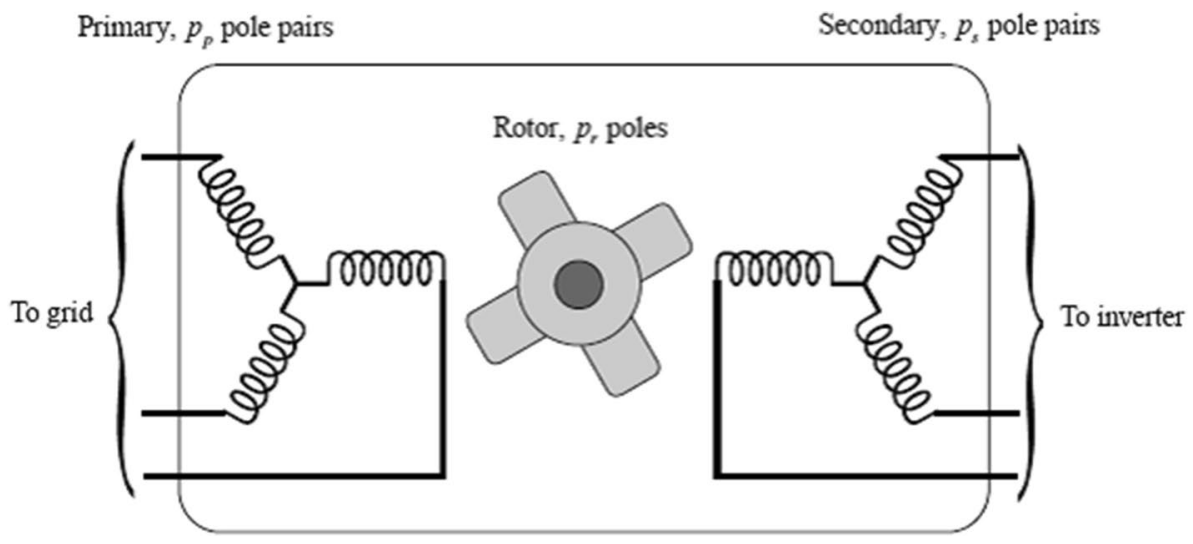


the maximum possible power at various wind speeds. The control of the generator must stabilize at a speed value matching the maximum power extracted from the wind turbine. Due to the maximum power extracted from the wind turbine taken only at one speed for the generator. At each wind speed found one generator speed for maximum power extracted, when connect these speeds with each other create track named maximum power point tracking [6].

\section{Dynamic model of brushless doubly fed reluctance generator}

The previously mentioned BDFRG has dynamic model shown in Fig. 2. This model is based on a theory called "the space vector" theory. Only special frame transformation for whole process of decoupling of both of the flux components and current components for producing electrical torque component can be applied. This is mainly because of the bizarre buildup of the BDFRG. The varying pole numbers for both of the power winding (primary winding) and the control winding (secondary winding) and different frequencies of their electrical quantities (current, flux, etc....) led to each winding to rotate by reference frame different than the reference frame for the other winding. The primary winding quantities rotating into a reference frame generally have a speed equal to $\omega$. Also the control winding quantities rotating into a reference frame generally have another speed equal to $\left(\omega_{r}-\omega\right)$ [3]. The speed of the reference frame of the power winding is preferred to have a magnitude equal to the network frequency. Equation (1) represents the dynamic model resulting from the two-frame transformation. The flux equations are given as Eq. (2). The torque and the mechanical speed expressions are represented as Eq. (3) [4, 5]:

$$
\begin{aligned}
& v_{\mathrm{dq}}=r_{\mathrm{p}} i_{\mathrm{dp}}+\frac{\mathrm{d}}{\mathrm{d} t} \lambda_{\mathrm{dq}}-\omega \lambda_{\mathrm{qp}} \\
& v_{\mathrm{qp}}=r_{\mathrm{p}} i_{\mathrm{qp}}+\frac{\mathrm{d}}{\mathrm{d} t} \lambda_{\mathrm{qp}}+\omega \lambda_{\mathrm{dp}} \\
& v_{\mathrm{dc}}=r_{\mathrm{c}} i_{\mathrm{dc}}+\frac{\mathrm{d}}{\mathrm{d} t} \lambda_{\mathrm{dc}}-\left(\omega_{r}-\omega\right) \lambda_{\mathrm{qc}} \\
& v_{\mathrm{qc}}=r_{\mathrm{c}} i_{\mathrm{qc}}+\frac{\mathrm{d}}{\mathrm{d} t} \lambda_{\mathrm{qc}}+\left(\omega_{r}-\omega\right) \lambda_{\mathrm{dc}}
\end{aligned}
$$

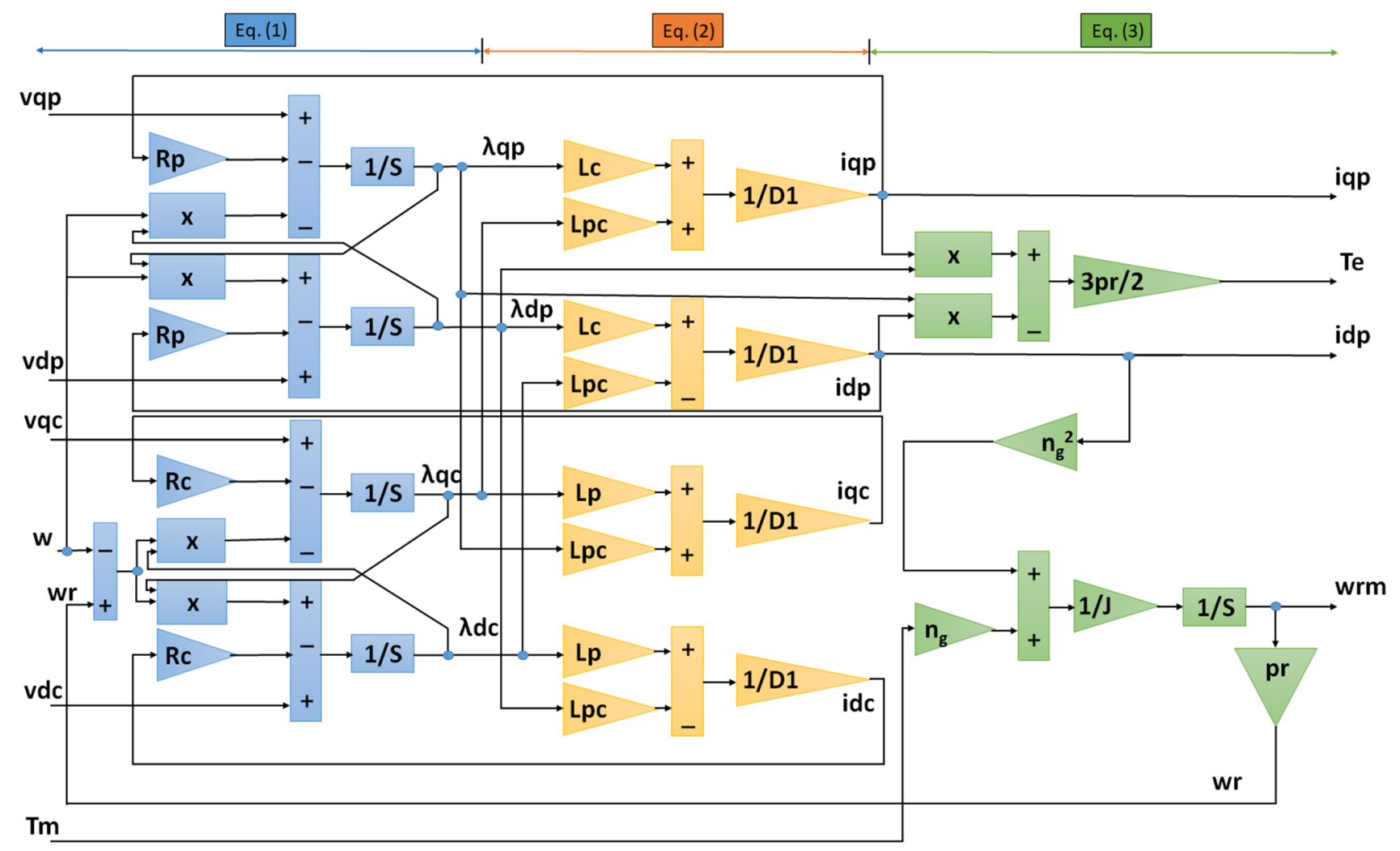

Fig. 2 Block diagram for dynamic simulation of a BDFRG in the arbitrary reference frame 
$\lambda_{\mathrm{dp}}=L_{\mathrm{p}} i_{\mathrm{dp}}+L_{\mathrm{pc}} i_{\mathrm{dc}}$

$\lambda_{\mathrm{qp}}=L_{\mathrm{p}} i_{\mathrm{qp}}-L_{\mathrm{pc}} i_{\mathrm{qc}}$

$\lambda_{\mathrm{dc}}=L_{\mathrm{c}} i_{\mathrm{dc}}+L_{\mathrm{pc}} i_{\mathrm{dp}}$

$\lambda_{\mathrm{qc}}=L_{\mathrm{c}} i_{\mathrm{qc}}-L_{\mathrm{pc}} i_{\mathrm{qp}}$

$T_{\mathrm{e}}=\frac{3}{2} p_{\mathrm{r}}\left[\lambda_{\mathrm{pd}} i_{\mathrm{pq}}-\lambda_{\mathrm{pq}} i_{\mathrm{pd}}\right]$

$\left(J_{\mathrm{r}}+n_{\mathrm{g}}^{2} J_{\mathrm{g}}\right) \frac{\mathrm{d} w_{\mathrm{rm}}}{\mathrm{d} t}=n_{\mathrm{g}} T_{\mathrm{m}}+n_{\mathrm{g}}^{2} T_{\mathrm{e}}$

where

$$
\begin{aligned}
D_{1} & =L_{\mathrm{p}} L_{\mathrm{c}}+L_{\mathrm{pc}}^{2} \\
J & =J_{\mathrm{r}}+n_{\mathrm{g}}^{2} J_{\mathrm{g}}
\end{aligned}
$$

Equation (4) shows the useful torque developed for the machine [4];

$w_{\mathrm{r}}=p_{\mathrm{r}} w_{\mathrm{rm}}=w_{\mathrm{p}}+w_{\mathrm{s}}$

\section{Wind turbine characteristics}

Equations (5) to (8) illustrate the power and the speed characteristics of a variable-speed wind turbines $[6,7]$ :

$P_{\mathrm{t}}=0.5 \rho \pi R^{2} C_{\mathrm{p}}(\lambda, \beta) V_{\mathrm{w}}^{3}$

The turbine tip-speed ratio $\lambda$ is given by:

$$
\lambda=\left(\frac{R \omega_{\mathrm{rm}}}{V_{\mathrm{w}} n_{\mathrm{g}}}\right)
$$

$C_{p}(\lambda . \beta)=0.5176\left(\frac{116}{\lambda_{x}}-0.4 \beta-5\right) e^{-\frac{21}{\lambda_{x}}}+0.0068 \lambda$

where

$\frac{1}{\lambda_{x}}=\frac{1}{\lambda+0.08 \beta}-\frac{0.035}{\beta^{3}+1}$

The MPPT technique function detects the preferable rotor speed related to the wind speed. Generator control systems are used for obtaining the optimal shaft speed. Some of the MPPT techniques need to measure the wind speed, while others don't need. This paper used the tipspeed ratio MPPT method. This method calculates the optimal rotor speed to achieve MPPT.

\section{Studied system}

As shown in Fig. 3, the system under study mainly consists of BDFRG driven by a wind turbine. The BDFRG has two converters for connecting the secondary winding with the grid. These converters named MSC and GSC each have a controller as shown in Fig. 3.

The first part from the MSC controller compared the reference speed extracted from MPPT method with actual speed for rotor. From this comparison, the resulting error

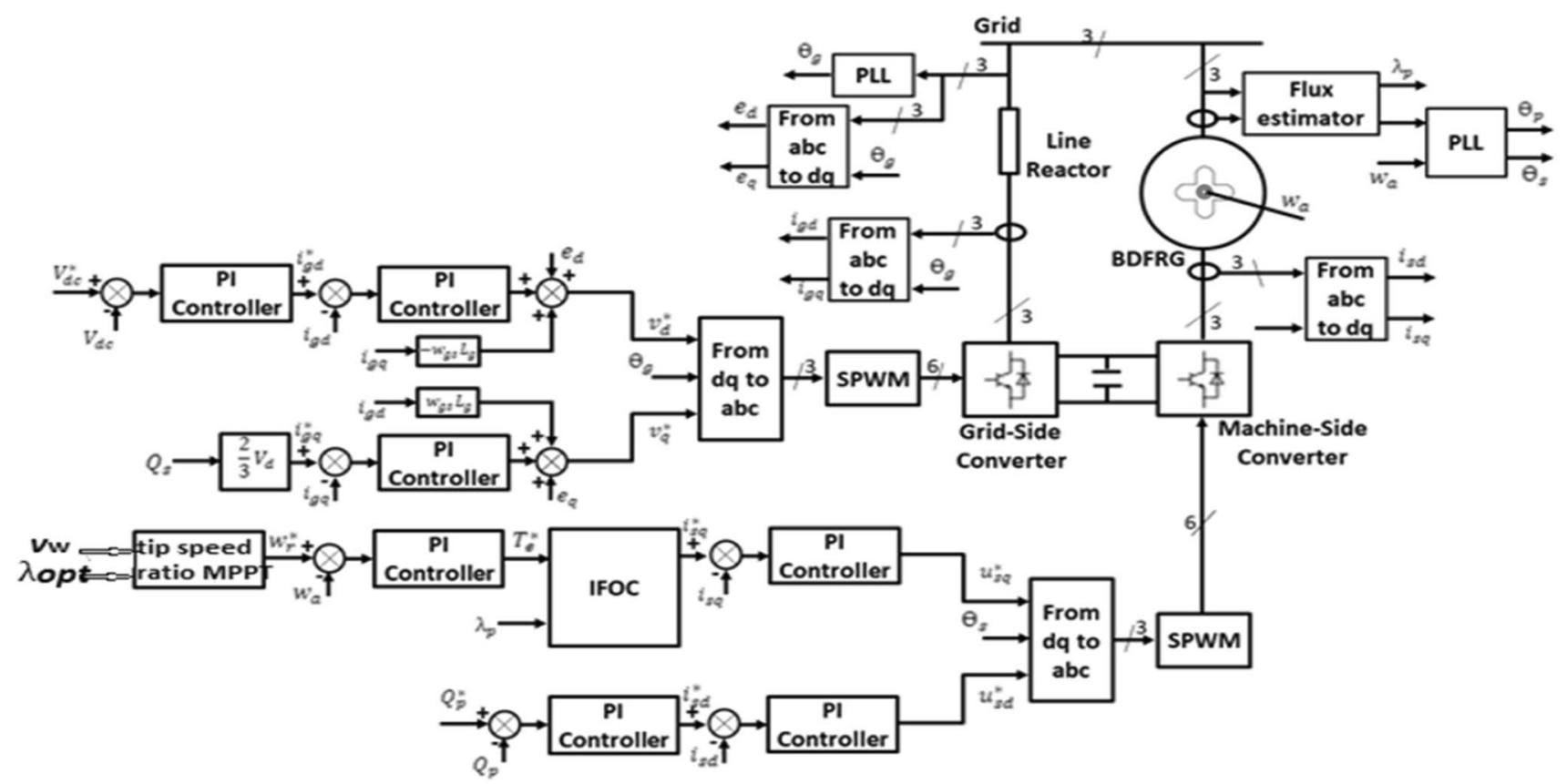

Fig. 3 System block diagram 
inter in a PI controller that will give the reference torque. The reference torque will be input in equation of indirect field-oriented control IFOC in order to give reference quadrature current. The reference quadrature current will be compared with actual quadrature current of the control winding. From this comparison, the resulting error inter in a PI controller that will give the reference quadrature voltage.

The second part from the MSC controller compared the primary reactive power with the reference reactive power (that equals zero in this study for unity power factor). From this comparison, the resulting error inter in a PI controller that will give the reference direct current. The reference direct current will be compared with the actual direct current of the control winding. From this comparison, the resulting error inter in a PI controller that will give the reference direct voltage.

The reference quadrature voltage results from the first part of the MSC controller, and the reference direct voltage results from the second part of the MSC controller transformed from dq frame to abc frame by using $\left(\theta_{s}\right)$. This transformation in order to obtain suitable gate signals for the switches of the MSC from SPWM.

\section{Simulation Results}

This simulation was carried out by the MATLAB/Simulink (2013b). The studied system is put in the overall system, as shown in Fig. 4. The data of the BDFRG and the data of the turbine are described in Table 1 [7].

Grid-side converter has three controllers as shown in Fig. 3, which are:
(1) DC voltage controller: it is the first controller that compares the actual DC link voltage with the reference value of the DC link voltage (equal to $710 \mathrm{~V}$ ).

(2) The second controller and the third controller produce the reference direct voltage and the reference quadrature voltage, respectively. These reference voltages are transformed from dq frame to abc frame. This transformation produces suitable gate signals for the switches of the GSC from SPWM.

Some results from the overall system under study were presented here. As illustrated from the results, the system approximately reaches steady-state condition after $0.4 \mathrm{~s}$ from the starting point.

Figures 5 and 6 show the power current and the control current of the BDFRG, respectively. The two currents have different frequencies (as mentioned above in order to produce torque from the BDFRG).

Figures 7 and 8 show the active power and the reactive power flow from or to transmission line at $380 \mathrm{~V}$ bus-bar. As obvious from the two figures, the BDFRG injects power to the grid and does not absorb reactive power from the grid (for unity power factor) after $0.4 \mathrm{~s}$ from the starting point.

Figures 9 and 10 show the shaft speed and the power coefficient. As obvious from the two figures, the rotor speed (or shaft speed) reaches the reference value in small time and the MPPT method reaches the maximum power extracted from the wind turbine (at a certain wind speed of $8 \mathrm{~m} / \mathrm{s}$ in this study), where the maximum power extracted from the wind turbine can be detected by the power coefficient value ( 0.48 in this study).

Figure 11 shows the DC link voltage, which is adjusted by a reference value after $0.4 \mathrm{~s}$ from the starting point (after reaching the steady-state condition).

Fig. 4 Overall system under study

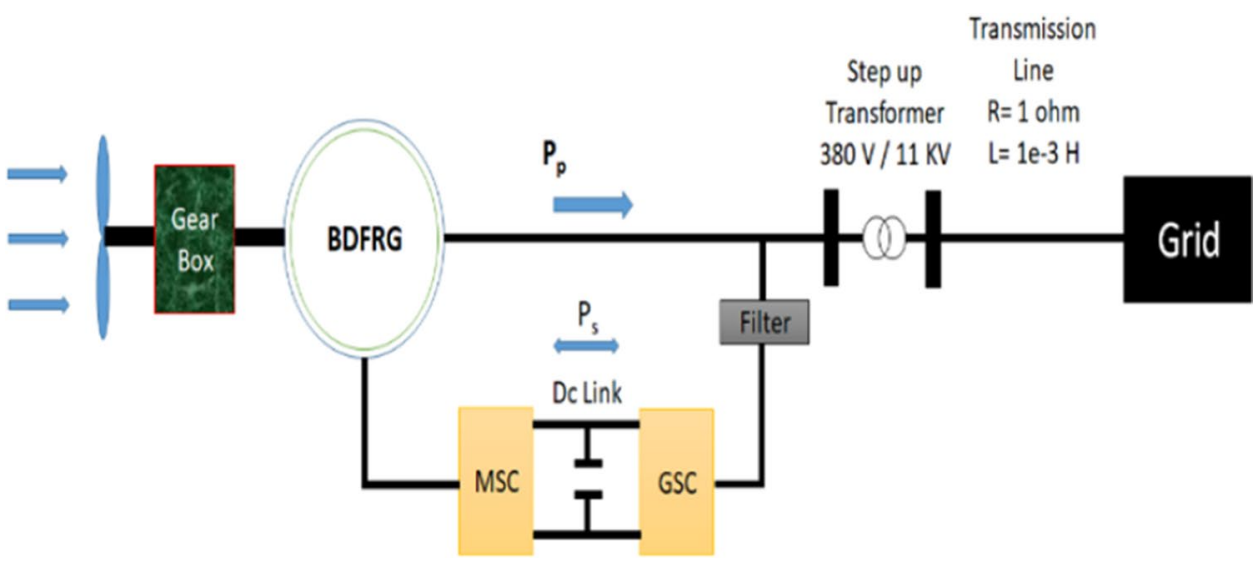


Fig. 5 Primary current of BDFRG

Fig. 6 Secondary current of BDFRG

Fig. 7 Active power at bus-bar on machine side
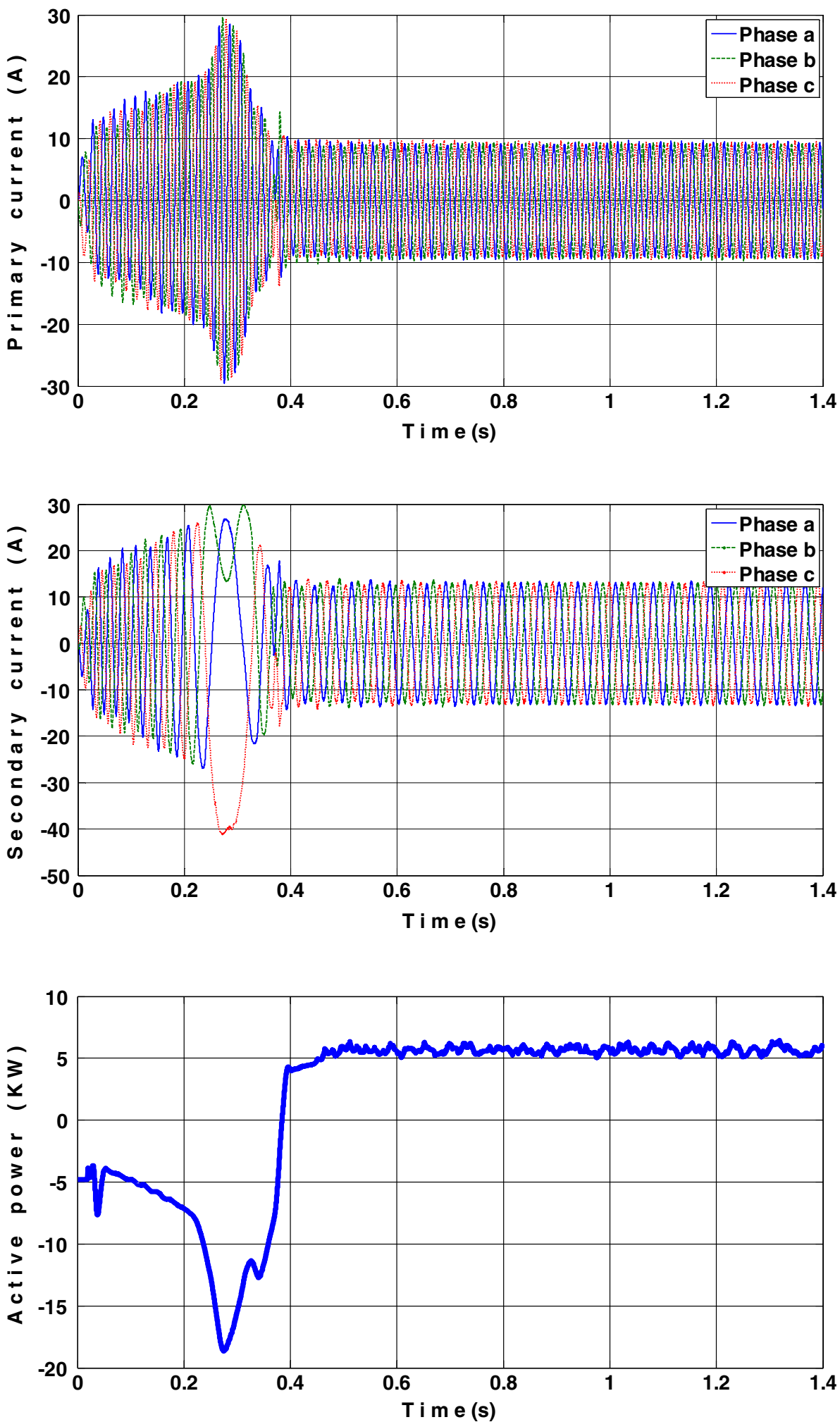
Fig. 8 Reactive power at busbar on machine side

Fig. 9 Shaft speed of BDFRG

Fig. 10 Power coefficient
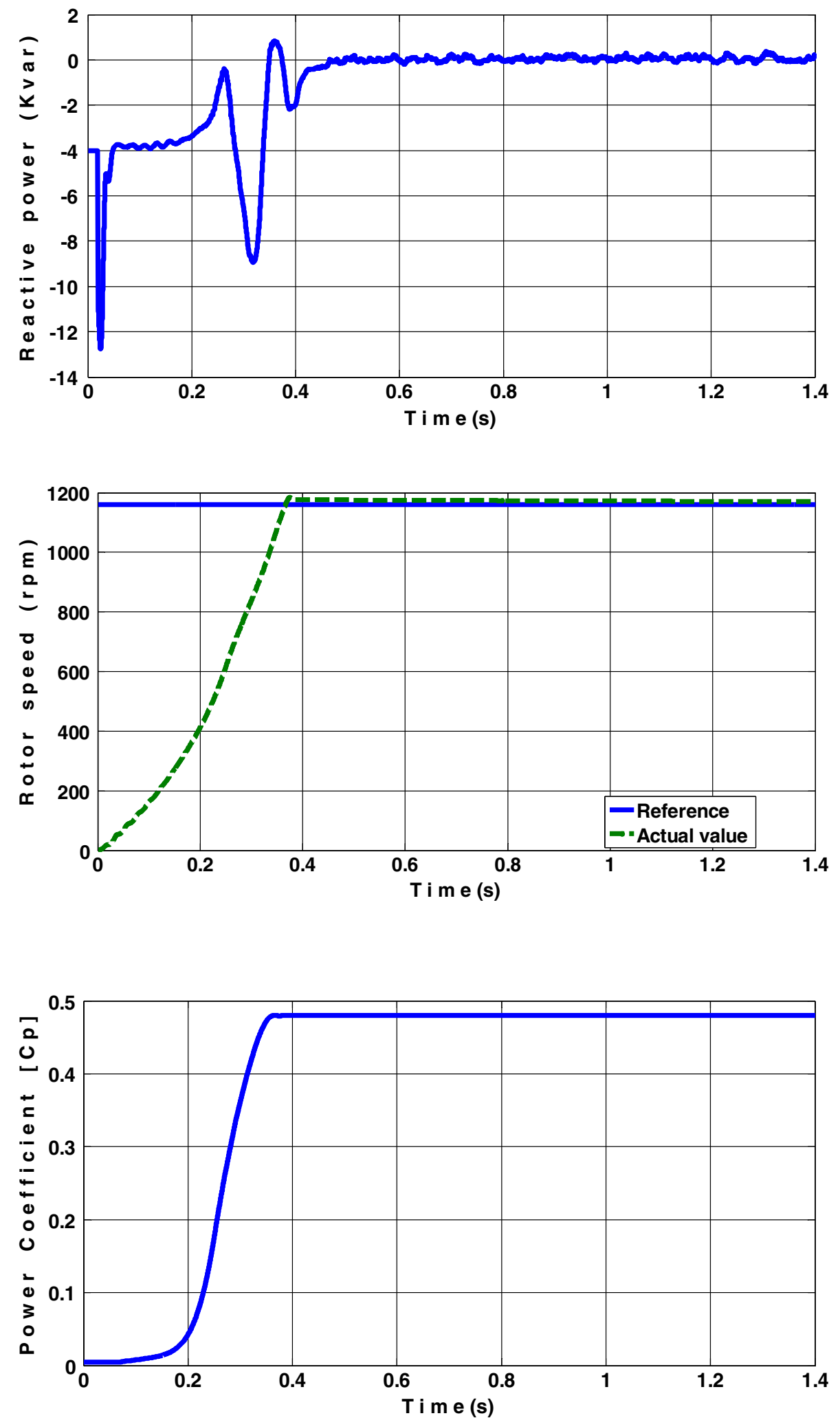
Fig. 11 DC link voltage

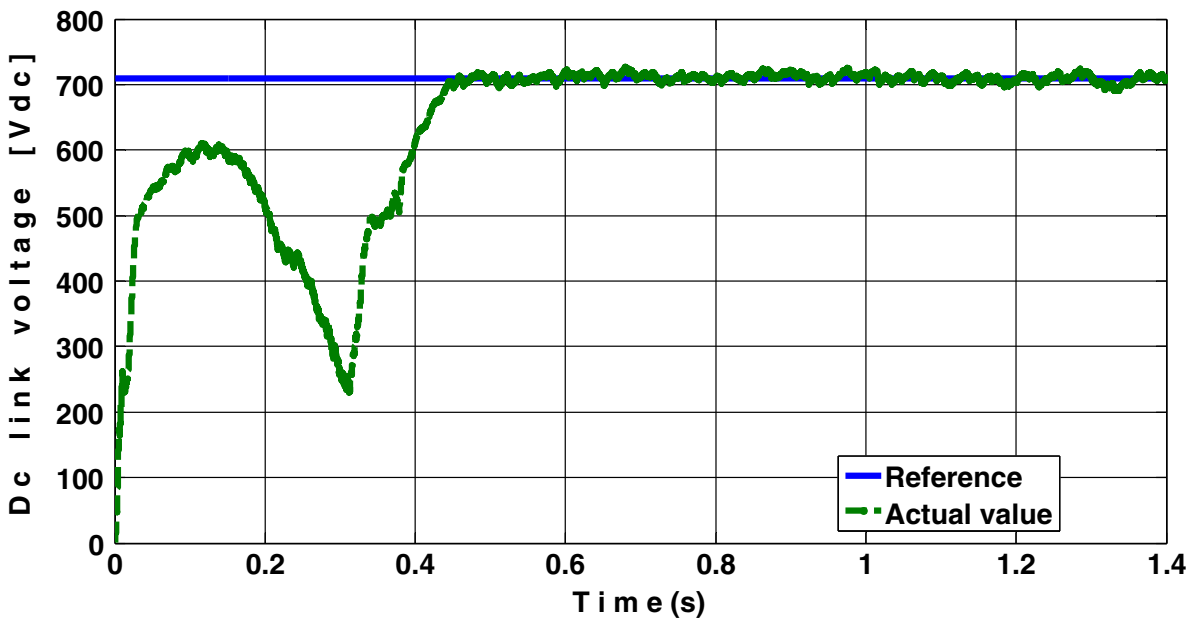

\section{Conclusion}

The grid-connected BDFRG model, control and its simulation can be show validity from results. As mentioned previously, all results approximately reach steady-state condition after $0.4 \mathrm{~s}$ from the starting point. The results of the primary current and the secondary current have different frequencies in order to produce electrical torque.

Active power delivers rated value to the grid after reaching the steady-state condition, while the reactive power has a zero magnitude (reference value) to improve the power factor. Rotor speed reaches reference value after a small time, and the reference value of the rotor speed is taken from MPPT method [tip-speed ratio in this study]. The power coefficient reaches a preferable value in order to extract a maximum power from the wind turbine [0.48 for this wind turbine]. Moreover, the DC link voltage reaches its reference value when the steady-state condition starts.

\section{Compliance with ethical standards}

Conflict of interest The author(s) declare that they have no conflict of interest.

\section{Appendix}

See Table 1.
Table 1 BDFRG parameters and wind turbine data

\section{BDFRG parameters}

Rated line voltage

Rated frequency

$380 \mathrm{~V}$

$r_{\mathrm{p}}$

$50 \mathrm{~Hz}$

$3.781 \Omega$

$r_{\mathrm{c}}$

$2.441 \Omega$

$L_{\mathrm{p}}$ $0.41 \mathrm{H}$

$L_{c}$ $0.316 \mathrm{H}$

$L_{\mathrm{pc}}$

$0.3 \mathrm{H}$

Wind turbine parameters

Rotor inertia, $J_{g}$

$0.2 \mathrm{~kg} \mathrm{~m}^{2}$

Rated power

$6 \mathrm{KW}$

Turbine radius, $R$

$4 \mathrm{~m}$

Wind speed range

$2-12 \mathrm{~m} / \mathrm{s}$

Turbine inertia, $J_{\mathrm{r}}$ $1.5 \mathrm{~kg} \mathrm{~m}^{2}$

Gearbox ratio, $n_{\mathrm{g}}$

\section{References}

1. Jovanović MG (2006) A comparative study of control strategies for performance optimisation of brushless doubly- fed reluctance machines. J Electr Syst 2(4):208-225

2. Jovanović MG, Betz RE, Yu J (2002) The use of doubly fed reluctance machines for large pumps and wind turbines. IEEE Trans Ind Appl 38(6):1508-1516

3. Betz RE, Jovanovic MG (1998) Introduction to brushless doubly fed reluctance machines. The Basic Equations

4. Jovanovi M, Chaal H (2010) High-performance control of doubly-fed reluctance machines 14(1):72-77 
5. Ademi S, Jovanovid M, Obichere JK (2014) Comparative analysis of control strategies for large doubly-fed reluctance wind generators. Lect Notes Eng Comput Sci 1:22-24

6. Mohamed A, Moniem A (2013) Sensorless MPPT technique for grid-connected PMSG wind turbine. Master thesis

7. Mousa MG, Allam SM, Rashad EM (2015) Maximum power tracking of a grid-connected wind-driven Brushless doubly-fed reluctance generator using scalar control. In: 2015 IEEE 8th GCC Conf. Exhib. GCCCE 2015, pp 1-4

Publisher's Note Springer Nature remains neutral with regard to jurisdictional claims in published maps and institutional affiliations. 